\title{
Guitar Playing Robot
}

\author{
Michal Kelemen *, Ivan Virgala, Tatiana Kelemenová, Lubica Miková and Peter Frankovský
}

${ }^{1}$ Technical University of Košice, Faculty of Mechanical, 04200 Košice

Abstract: The paper deals with guitar playing robot, which is able to play any song. Paper explores only electromechanical parts of robot with aim to build prototype of the robot. Robot is dedicated for educational purpose. Also functional experiments have been executed with actuators for strumming and also own concept of actuator has been developed for pushing of string.

Keywords: guitar robot, actuator, sensor, servo.

\section{Introduction}

Guitar as music instrument belongs to category of string instruments. Preloaded steel wire is used for generating of tones. There are several famous activities in this are like robotic guitar, which can replace group of three guitarists. Guitar robot has guitar-strumming mechanism and playing is precise and much faster than human playing (fig. 1).
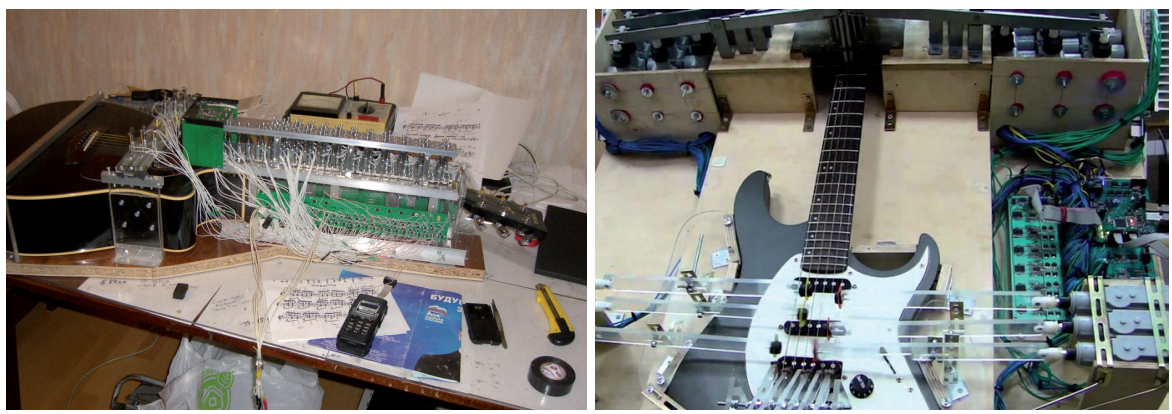

Fig. 1: Robotic guitar.

Z-Machines (fig. 2) is the robot band, which contains also guitarist robot with 78 fingers sweeping across the glowing instrument strapped to its torso. Z-Machines are created by engineers at the University of Tokyo, the robot band uses around 300 kilowatts of electricity. "Just like when you're writing music for a human, there are certain possibilities and certain limits. The robot guitarist for example, can play much faster than a human ever could, but there is no amplification control.".
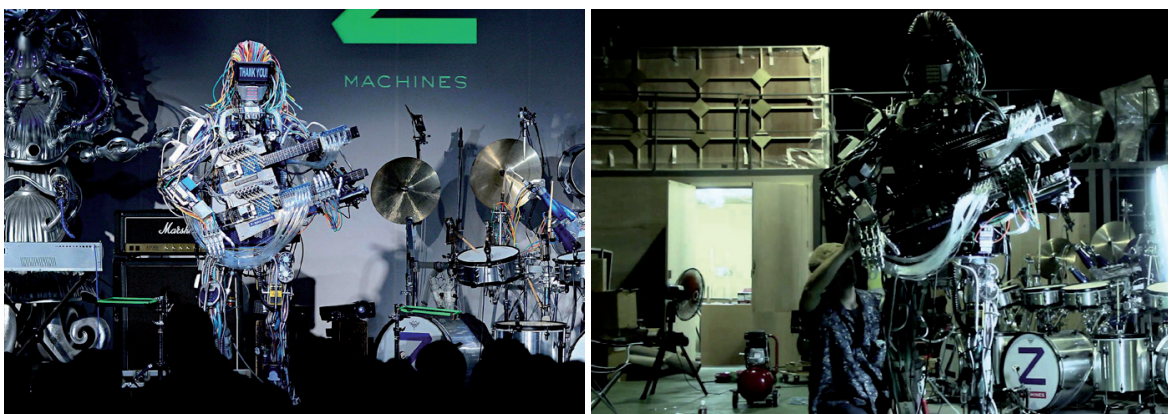

Fig. 2: Z-Machines - guitar robot. 
Aim of this work is to design guitar robotic system. Limiting conditions are:

- robot will play on standard spanich guitar, - guitar cannot be damaged with holes, glue or other bonding technologies.

\section{Basic assumptions and description of the problem}

There is an equation between the stress and deformation of guitar spring wire (if we suppose the elastic deformation in range of validity of Hooke law):

$$
\sigma=\frac{F}{S}=E \cdot \frac{\Delta L}{L_{0}}
$$

where: $\sigma$ - stress in spring wire, $F$ - axial force of tightening, $E$ - Youngs modulus, $\Delta L$ - deformation, $L_{0}$ - initial length of spring wire.

Guitar wire is made from music wire (ASTM A228) with high strength and excellent fatigue life $(\mathrm{E}=207 \mathrm{GPa})$.

To get the correct tone from the string, a approximately preload tension of $200 \mathrm{~N}$ has to be applied.

Sound wave is created as a result of a vibrating object. The vibrating object is the source of the disturbance that moves through the medium. Any object that vibrates will create a sound. The sound could be musical or it could be noisy; but regardless of its quality, the sound wave is created by a vibrating object. Nearly all objects, when hit or struck or plucked or strummed or somehow disturbed, will vibrate. If you pluck a guitar string, it will begin to vibrate. The frequency or frequencies at which an object tends to vibrate with when hit, struck, plucked, strummed or somehow disturbed is known as the natural frequency of the object. If the amplitudes of the vibrations are large enough and if natural frequency is within the human frequency range, then the vibrating object will produce sound waves that are audible. The actual frequency at which an object will vibrate at is determined by a variety of factors. Each of these factors will either affect the wavelength or the speed of the object. Since frequency $=$ speed/wavelength an alteration in either speed or wavelength will result in an alteration of the natural frequency. The role of a musician is to control these variables in order to produce a given frequency from the instrument that is being played.

Guitar generally has six strings, each having a different linear density (the wider strings are more dense on a per meter basis), a different tension (which is controllable by the guitarist), and a different length (also controllable by the guitarist). The speed at which waves move through the strings is dependent upon the properties of the medium - in this case the tightness (tension) of the string and the linear density of the strings. Changes in these properties would affect the natural frequency of the particular string. The vibrating portion of a particular string can be shortened by pressing the string against one of the frets on the neck of the guitar. This modification in the length of the string would affect the wavelength of the wave and in turn the natural frequency at which a particular string vibrates at. Controlling the speed and the wavelength in this manner allows a guitarist to control the natural frequencies of the vibrating object (a string) and thus produce the intended musical sounds. The same principles can be applied to any string instrument - whether it is the harp, harpsichord, violin or guitar.

Once the speed of propagation is known, the frequency of the sound produced by the string can be calculated. The speed of propagation of a wave is equal to the wavelength $\lambda$ divided by the period $\tau$, or multiplied by the frequency $f$ :

$v=\frac{\lambda}{\tau}=\lambda \cdot f$

where: $\lambda$ - wavelength, $\tau$ - period, $f$-frequency.

If the length of the string is $L$, the fundamental harmonic is the one produced by the vibration whose nodes are the two ends of the string, so $L$ is half of the wavelength of the fundamental harmonic. Hence one obtains Mersenne's laws:

$$
f=\frac{v}{2 \cdot L}=\frac{1}{2 \cdot L} \cdot \sqrt{\frac{T}{\mu}}
$$

where: $T$ - tension of string, $\mu$ - linear density of string (mass per unit length), $L$ - length of vibrating string.

Therefore: the shorter the string, the higher the frequency of the fundamental; the higher the tension, the higher the frequency of the fundamental; the lighter the string, the higher the frequency of the fundamental. 
Consequently, playing on guitar consists of two activities - strumming and pushing of strings. Also concept of robot will consist of two mechanisms for ensuring of these activities. Encompassment of these problems will need very good design of mechanical parts and actuators for strumming and pushing. Also new own concept of actuator has been developed for pushing of string.

\section{Experiment with strumming actuators}

Basic principle of sound generating is resounding (vibration) of preloaded guitar wire string. This generating is possible to make through the linear or swinging motion. Wire is axially preloaded and it is complicated to count minimum force for vibration making. That is the reason of experimentally way solution of the problem (fig. 3). Three servos have been selected for strumming experiment:

- Hitec HS 55 (maximum torque $1.3 \mathrm{Nm}$, maximum velocity $0.98 \mathrm{rps})$,

- Hitec HS 82 (maximum torque $3.4 \mathrm{Nm}$, maximum velocity 1.38 rps),

- Hitec HS 645MG (maximum torque $9.6 \mathrm{Nm}$, maximum velocity 0.69 rps).

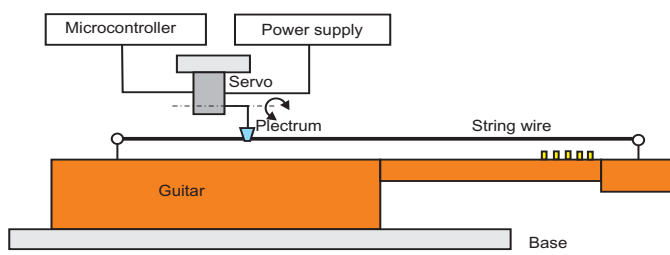

Fig. 3: Scheme of the strumming actuator experiment.

Servos have been controlled via using the microcontroller Basic Atom Pro 28-M (fig. 3, fig. 4), which has wide possibilities of servo controlling (parallel controlling of up to 32 servos, hardware controlling servo on background, get servo position, waiting for servo position etc.). Guitar plectrum has been attached to servo horn. Every servo has been controlled for swinging motion in range 30 degree.

Only HS 645MG has been passed in the experiment (fig. 4). Other two servos were not able to make suitable string vibration.

\section{Pushing of strings}

Important role of guitar robot is pushing of strings. Place of string pushing changes generated frequency of tone. Solenoid electromagnetic

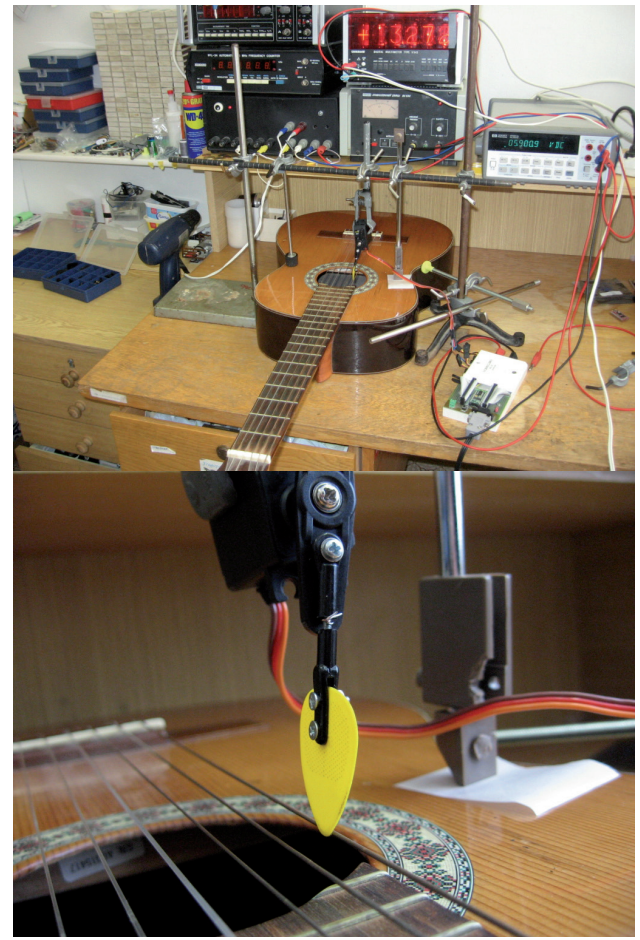

Fig. 4: Strumming experiments with actuators.

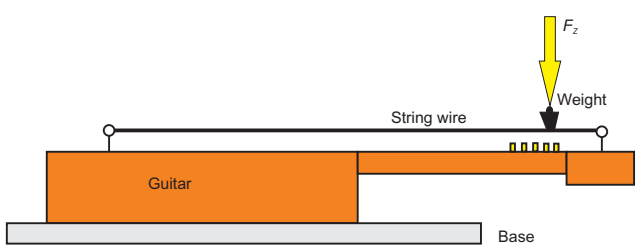

Fig. 5: Pushing force experiment.

actuator has been selected for this purpose. Next experiment gives the information about the value of pushing force. This value is necessary for solenoid actuator design.

Etalon weights were used for identification of pushing force. Experiment showed that minimum force is $5 \mathrm{~N}$ for pushing of string with maximum stiffness (maximum string diameter).

Solenoid electromagnetic actuator force (fig. 6) is defined with equation:

$F_{A}=\frac{F_{m}^{2} \cdot \mu_{0} \cdot A_{C}}{2 \cdot d_{G A P}^{2}}$

where: $F_{A}$ - solenoid force (N), $N$ - numebr of turns in coil, $I_{C}$ - current through the coil (A), $A_{C}$ - area of coil core $\left(\mathrm{mm}^{2}\right), d_{G A P}$ - air gap between the core and yoke of coil (mm). 
The maximum distance between the spring wire and guitar sleeper is $5 \mathrm{~mm}$. It means that maximum stroke of electromagnetic actuator should be $5 \mathrm{~mm}$. Air gap will be adjusted to $5 \mathrm{~mm}$ via using the adjusting screw (fig. 6).
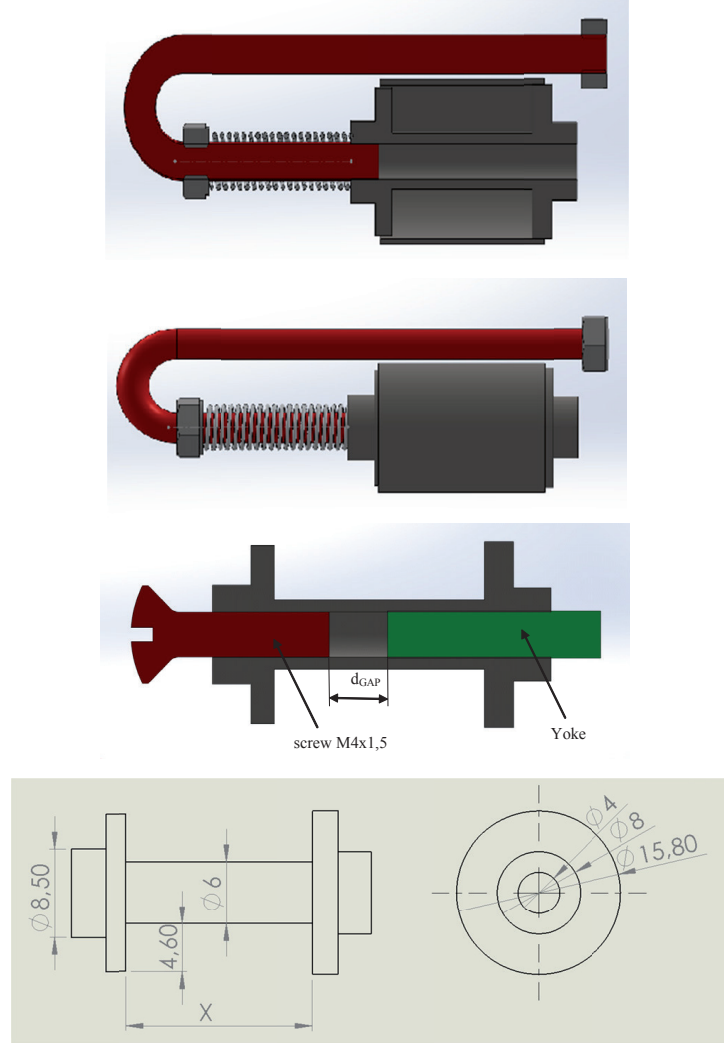

Fig. 6: Designed solenoid electromagnetic actuator.

On the base of approximate calculation using the equation 1 have made several various test coils (fig. 7) for solenoid actuator. Parameter X (fig. 6) was changed for every tested piece. The maximum distance between the spring wire and guitar sleeper is $5 \mathrm{~mm}$. It means that maximum stroke of electromagnetic actuator should be $5 \mathrm{~mm}$.

Designed actuator with experimental coil has been tested in measuring stand (fig. 8). Measured parameters were pushing force and heating of the coil. The best results were obtained from experiments with last coil (fig. 7), which has the biggest length. This coil has minimum heating and has maximum pushing force. Excitation current was 3A.

Guitar robot will consist of 36 pieces of solenoid actuator arranged on guitar on fixed positions

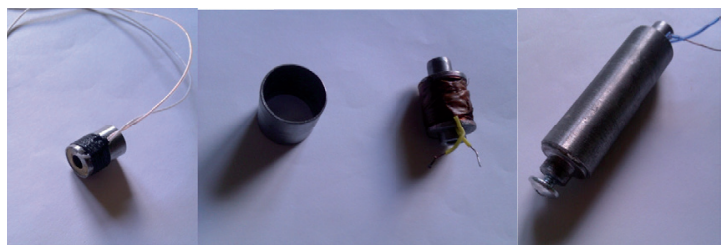

Fig. 7: Experimental coils for string pushing actuator.

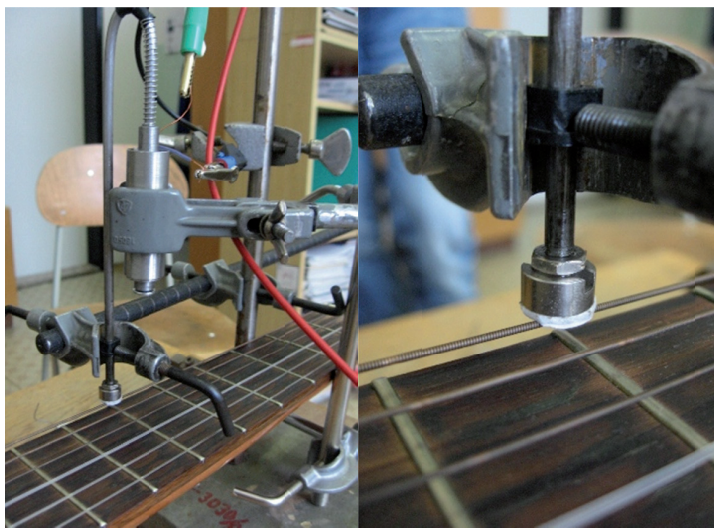

Fig. 8: Testing of solenoid actuator for pushing of the spring wire.

(fig. 9).Coil Yoke is loaded with combination of eccentric pressure and bending and it has been checked via using the finite element method (FEM) (fig. 10). The maximum stress in coil yoke has value $8 \mathrm{MPa}$ and maximum deformation is less than $0.05 \mathrm{~mm}$.
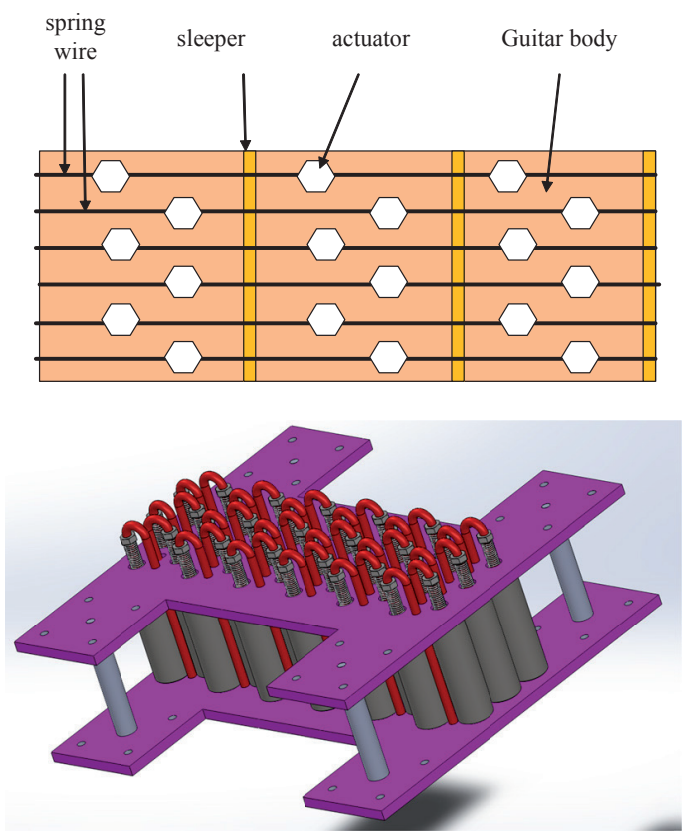

Fig. 9: Solenoid actuators placement on guitar. 


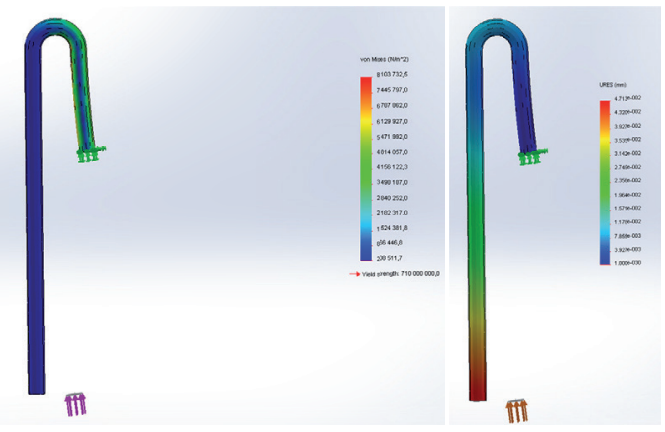

Fig. 10: FEM of actuator yoke.

\section{Overall arrangement}

Overall design is shown on figure 11. The arrangement allows playing of much complicated songs because the every string has independent servo with guitar plectrum and also there are 36 pieces of solenoids. All these possibilities overcome the human fingers. All these actuators can be controlled via using the microcontroller or other control system.

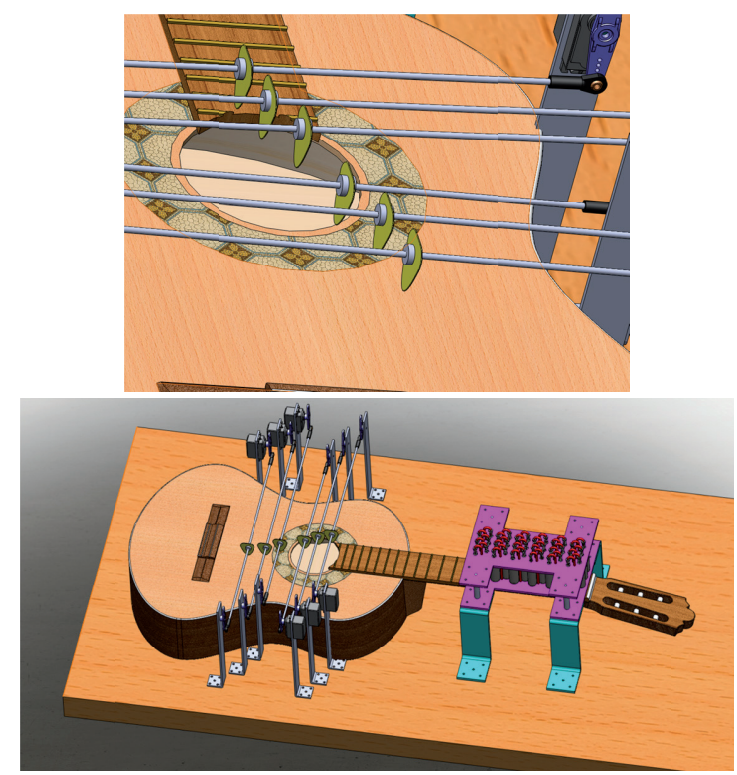

Fig. 11: Overall arrangement design of guitar robot.

\section{Conclusions}

The proposed robot is not for commercial use. It is designed as didactic tool for subjects as microcontroller or embedded systems. Other problems, which is not solved up this moment is algorithm of song coding to actuators commands. This didactic tool help to students understand of basic principles of actuators and exciting of them via using of embedded systems. It will help to develop knowledge, skills and experiences of our students.

\section{Acknowledgments}

The authors would like to thank to Slovak Grant Agency project VEGA 1/0872/16.

\section{References and Notes}

[1] Kevin, Lee. (2012): This Robotic Guitar Can Replace Three Guitarists, TechHive, 2012, available online, original paper from May 24, 2012 10:22 AM, cited07-30-2016. http://www. techhive.com/article/256184/this_robotic_guitar_can_replace_three_guitarists.html

[2] Guzanová, Anna et al. (2017): Influence of build orientation, heat treatment, and laser power on the hardness of Ti6Al4V manufactured using the DMLS process, In: Metals. Vol. 7, no. 8 (2017), p. 1-17. ISSN 2075-4701

[3] McKenzie, S., for CNN: Meet the robot guitarist with 78 fingers and coolest cable hair you've ever seen. Art of Movement. Available online, original paper updated 7:39 AM EDT, Fri March 14, 2014. Cited 08-07-2016. http://edition.cnn. com/2014/03/14/tech/meet-the-robot-guitarist/

[4] The Physics Classroom » Physics Tutorial »Sound Waves and Music » Natural Frequency. available online. Cited 0825-2016. http://www.physicsclassroom.com/class/sound/ Lesson-4/Natural-Frequency.

[5] Balogová, A. et al. (2016): Determination of scaffolds properties from specific material made by aditive manufacturing, 2016. In: YBERC 2016. - Ostrava : VŠB-TU, 2016 S. 1-5. ISBN 978-80-248-4000-0

[6] String vibration. Wikimedia Foundation, Inc... Available online. 2008) Cited 08-25-2016. https://en.wikipedia.org/wiki/ String_vibration.

[7] Molteno, T. C. A.; N. B. Tufillaro (September 2004). "An experimental investigation into the dynamics of a string". American Journal of Physics. 72 (9): 1157-1169.

[8] Tufillaro, N. B. (1989). "Nonlinear and chaotic string vibrations". American Journal of Physics. 57 (5): 408.

[9] Poláček I., Hudák R., Živčák J. (2016): Wireless sensing of the temperature in vivo for implantological applications, Trends of education and research in biomedical technologies 2016, Košice, ISBN 987-80-8152-470-7

[10] Dekan, M., Duchoň, F., Jurišica, L., Vitko, A., Babinec, A.,: iRobot Create Used in Education. In: Journal of Mechanics Engineering and Automation. ISSN 2159-5275. Vol. 3, Iss. 4 (2013), s. 197-202.

[1 1] Koniar, D., Hargaš, L., Hrianka, M.: Application of standard DICOM in LabVIEW. Proc. of 7th conf. Trends in Biomedical Engineering, Kladno 11. - 13. 9. 2007 ISBN 978-80-01-03777-5. 2007. 
[12] Hargaš, L., Hrianka, M., Koniar, D., Izák, P.: Quality Assessment SMT Technology by Virtual Instrumentation. Applied Electronics 2007, Pilsen, 5. - 6. 9. 2007, ISBN 987-80-7043-537-3, 2007.

[13] Duchoň, F., Dekan, M., Jurišica, L., Vitko, A.: Some Applications of Laser Rangefinder in Mobile Robotics. In: Journal of Control Engineering and Applied Informatics. - ISSN 14548658. - Vol. 14, No. 2 (2012), s. 50-57

[14] Poláček, I. et al. (2016): A geometrical accuracy of subtractive and additive technologies in dental production is comparable. In: YBERC 2016. - Ostrava : VŠB-TU, 2016 P. 1-5. ISBN 978-80-248-4000-0

[15] Balogová, A. et al. (2016): The determination of geometrical and viscoelastic properties of scaffolds from polylactic acid and polyhydroxybutyrate made by additive manufacturing In: YBERC 2016. - Ostrava : VŠB- Ostrava, 2016 S. 1-6.

[16] Hanzel, J., Duchoň, F., Rodina, J., Pásztó, P.: Global Navigation Systems for Mobile Robots. In: International Journal of Systems Applications, Engineering \& Development. - ISSN 2074-1308. - Vol. 7, Iss. 5 (2013), s. 279-285.

[17] Tölgyessy, Michael - Chovanec, L'uboš - Pásztó, Peter - Hubinský, Peter: A Plane Based Real-Time Algorithm for Controlling a Semi-Autonomous Robot with Hand Gestures Using the Kinect. In: International Journal of Imaging and Robotics. - ISSN 2231-525X. - Vol. 13, Iss. 2 (2014), s. 126-133.

\section{Biographical notes}

Michal Kelemen, prof. Ing. PhD. He received M.S. degree in mechanical engineering from Technical University of Košice, Slovakia in 1998 and Ph.D. degree in Mechatronics from Technical University of Košice, Slovakia in 2002. He is an professor of the Department of Mechatronics at the Faculty of Mechanical Engineering at the Technical University of Košice, Slovakia. He has been awarded the 1998 "Price of the VolksBank" for the best M.S. graduate and 2007 Price "Scientist of the year". His research interests include mechatronic systems, intelligent robotic systems, dust mass concentration measurement, measurement of non-electric quantities, and microcomputer systems. He has authored more than 250 journal and conference papers on these topics.

Ivan Virgala, doc. Ing. PhD. He received M.Sc. degree in Mechatronics from Technical University of Košice, Slovakia in 2009 and PhD. degree in Mechatronics from Technical University of Košice, Slovakia in 2012. He is a researcher in Department of Mechatronics at Faculty of Mechanical Engineering at Technical University of Košice, Slovakia. He has been awarded by "medal of dean" for excellent study. He is an editorial board member of 3 foreign scientific journals. His research field is design, modeling and control of manipulators, mobile robots, snake robots, humanoid robots and embedded systems. He has authored more than 100 journal and conference papers on these topics.

Tatiana Kelemenová, doc. Ing. PhD. She received M.S. degree in mechanical engineering from Technical University of Košice, Slovakia in 1996 and Ph.D. degree in Mechatronics from Technical University of Košice, Slovakia in 2005. She is an associate professor of the Department of Biomedical Engineering and
Measurement at the Faculty of Mechanical Engineering at the Technical University of Košice, Slovakia. Her research interests include engineering metrology, measurement of non-electric quantities, mechatronic systems. She has authored more than 140 journal and conference papers on these topics.

Lubica Miková, Ing. PhD. She received M.S. degree in mechatronics from Technical University of Košice in 2007 and Ph.D. degree in Mechatronics from Technical University of Košice, Slovakia in 2011. She is a researcher of the Department of Mechatronics at the Faculty of Mechanical Engineering at the Technical University of Košice, Slovakia. Her research interests include mechatronics systems and robotics. She has authored more than 80 journal and conference papers on these topics.

Peter Frankovský, doc. Ing. PhD. He received M.S. degree in applied mechanics from Technical University of Košice, Slovakia in 2006 and Ph.D. degree in Applied Mechanics from Technical University of Košice, Slovakia in 2010. He is an associate professor of the Department of Mechatronics at the Faculty of Mechanical Engineering at the Technical University of Košice, Slovakia. His research interests include mechatronic systems, applied mechanics and experimental mechanics. He has authored more than 150 journal and conference papers on these topics. 